\title{
Healthcare Facility Evacuations: Lessons Learned, Research Activity, and the Need for Engineering Contributions
}

\author{
Ashley Kay Childers* and Kevin M. Taaffe, $\mathbf{P h D}^{\dagger}$ \\ Department of Industrial Engineering, 110 Freeman Hall, Clemson University, \\ Clemson, South Carolina 29634 \\ *akchild@clemson.edu, ${ }^{\dagger}$ taaffe@clemson.edu
}

\begin{abstract}
Over the past few years, there has been an increase in research related to a healthcare facility's role during a disaster. Most of this literature relates to emergencies where the facility is a resource to the affected population, and the facility must make decisions associated with sudden, increased patient demands. Some emergencies, however, may affect the facility's ability to function and may therefore force the need for a complete patient evacuation. This paper provides an overview of the available literature including lessons learned from actual healthcare facility evacuations and research focusing on making improvements. The purpose is to summarize a variety of healthcare evacuation issues and highlight the research in this area. We raise questions for further research and conclude with an example of using engineering techniques to improve healthcare facility evacuations by prioritizing patients for transport.
\end{abstract}

\section{INTRODUCTION}

Emergency preparedness and response has been researched for decades. However, since 9/11 and several other large-scale disasters (Hurricane Katrina, wildfires, tsunamis, etc.), there has been an additional focus on the preparation for, or response to, mass casualty emergencies. In fact, several papers specifically address triaging incoming patients (to evaluate the need and benefit of medical resources) and/or creating surge capacity in hospitals after a mass casualty event [e.g. 1 - 4]. There is significantly less research that considers healthcare facilities as the victims of these emergencies [5-8].

A healthcare facility may be the victim of an emergency if 1) its resources are overwhelmed with sudden and unexpected demands, or 2) the emergency causes - or presents potential for - damage to the facility. Terrorist attacks, pandemic outbreaks, or some other type of external emergency may cause this first scenario. In these types of emergency situations, a hospital may be expected to be a resource for response efforts. A fire, flood, bomb threat, or other internal emergency, may cause the second scenario. Hurricanes or other natural disasters may cause both. In order to meet the demands of a possible patient surge, or to continue to care for existing patients, a hospital may have to evacuate some or all of its occupants. Depending on the type of facility, less critical 
care patients can be discharged early, but those that need continued care will have to be transferred to another facility. Other emergencies may require a small area of a facility to temporarily evacuate some of its patients to directly outside of the facility, but these patients can usually return to their beds within a reasonable amount of time. A partial facility evacuation is much more common than a complete evacuation, and facilities usually have a variety of system redundancies in place so that they will not have to shut down. This research focuses on full evacuations where all patients in the facility are at risk due to some type of internal or external emergency.

Every healthcare facility is required to have an evacuation plan in place [9-12], and although considered a last resort, it is almost certain that every healthcare facility has the potential for some sort of emergency that would require patient transfers.

The evacuation literature typically relates to how the general population responds to and moves away from danger [e.g., 13], and there are a number of traffic models to help prepare for a mass evacuation [14 - 16]. As for evacuations specific to healthcare facilities, there is no source for collecting information; many papers point out this lack of historical hospital evacuation data [10, 11, 17]. In 2003, Sternberg et al. [11] conducted an investigation into the causes of hospital evacuations between 1971 and 1999 and made a number of assumptions, but we know that there were many highly-publicized evacuations during the 2004 and 2005 hurricane seasons. Schultz et al. [10] created a standardized data collection survey for hospital evacuations that addresses hospital demographics, characteristics of the emergency plan, as well as decision making and patient movement during the event. To our knowledge, however, there have not been any articles that discuss the implementation of this data collection tool.

In this paper, we provide an overview of the critical elements of healthcare facility evacuations as identified during actual patient transfers (Section 2) as well as a discussion of the current research related to improving healthcare facility evacuations (Section 3). In Section 3, we also discuss the need for research to develop and improve strategies for safely transporting patients away from a healthcare facility. In Section 4, we give an example of dynamic programming and simulation modeling to improve evacuations. In our research, we are using dynamic programming and simulation to develop and test policies for prioritizing patients for transport.

Before continuing to the following sections, it is important to consider how the nature of an emergency influences the evacuation response. If a facility has to evacuate because of a hurricane - or some other forecasted event - the administrative and clinical staff have likely had some sort of decision window to prepare for patient transfers. In such cases, an Incident Command Center is likely established. Healthcare facilities usually implement at least one of the following generalized coordination structures to address decision making: the Hospital Incident Command System (HICS) [18] or the National Incident Management System (NIMS) [19]. Both of these emergency management systems utilize a central Incident Command System (ICS) and can actually be used in conjunction with each other or with one of the other emergency response systems. The authors recognize that evacuation planning involves HICS and/or NIMS. These are keys to planning for disasters, but are beyond the scope of discussion in this article. 
Evacuation plans address how to handle fires or other emergencies that cause immediate danger to the facility, and these types of emergencies may likely require an immediate response. In the event of a no-notice emergency, there may not be time for Incident Command to set up and delegate assignments, and the staff will have to act instantaneously. If researchers learn more about healthcare facility evacuations, we can provide tools to aid in decision making before and during patient transfers. The insights of the research can be written into evacuation plans and training exercises as guidelines to help the staff prepare for real-time decisions in any length of evacuation window.

\section{KEY LESSONS LEARNED FROM PAST HEALTHCARE EVACUATIONS}

In this section, we outline the lessons learned from the real-time decisions and experiences from actual healthcare facility evacuations. The following papers describe emergency events and were used to summarize the lessons learned in Sections 2.1 - 2.6.

- $\quad$ Sternberg et al. [11] investigated databases to make assumptions about the types of hazards that resulted in 275 hospital evacuations in the United States between 1971 and 1999. Over half of these evacuations could be primarily attributed to internal emergencies.

- Schultz et al. [7] created and issued a questionnaire to personnel at area hospitals that were on duty during the Northridge, California earthquake. The earthquake resulted in eight hospital evacuations: six were evacuated with 24 hours of the earthquake, one evacuated 3 days after the earthquake, and one evacuated 2 weeks after the earthquake. For the six hospitals that evacuated soon after the earthquake, the decision to evacuate was based on non-structural damage. The other two hospitals had to evacuate patients because of non-repairable structural damage.

- Cocanour et al. [20] describe the "Lessons Learned From the Evacuation of an Urban Teaching Hospital" after Tropical Storm Allison caused flooding and forced the full evacuation of Texas Medical Center.

- Bowers et al. [6] describe the lessons learned from the perspective of Texas Medical Center's entire hospital system.

- Hyer et al. [21] documented the experiences of almost 300 nursing homes during the 2004 Hurricane Season. Approximately $16 \%$ of facilities had to evacuate at least once.

- Augustine and Schoettmer [22] describe a complete evacuation forced by a bomb threat. The staff of Galion Community Hospital in Columbus, Ohio evacuated all of its patients to a single, similar-sized facility located 20 miles from their hospital.

- Bovender and Carey [23] summarize the experiences and lessons learned from the evacuation of Tulane Hospital after Hurricane Katrina.

- Gray and Hebert [24] conducted interviews with hospital executives, public officials, and others in New Orleans-area hospitals to summarize the effects of evacuations conducted before and after Hurricane Katrina.

- Castro et al. [25] distributed surveys to assess the response of long-term care facilities during Hurricanes Katrina and Rita. 
- Dosa et al. [8] interviewed twenty nursing home administrative directors about the evacuation decisions made during Hurricanes Katrina and Rita.

- $\quad$ Laditka et al. [26] describe the care of nursing home evacuees after transport based on interviews with staff members in receiving facilities after Hurricane Katrina.

- $\quad$ Hyer et al. [27] describe need for improvements as identified at the "Hurricane Summit" in 2006. This report pertains to the preparation for and response to emergencies at long-term acute care facilities.

- The U.S. Government Accountability Office's "Limitations in Federal Evacuation Assistance for Health Care Facilities Should be Addressed" [28] discusses the federal government's involvement in hospitals' and nursing homes' preparation for evacuation.

- A report from the Office of Inspector General evaluates "Nursing Home Emergency Preparedness and Response During Recent Hurricanes" [12] by analyzing survey and interview responses as well as emergency plans.

- Lewis [29] describes the evacuation response and lessons learned after a tornado damaged a facility in Georgia in 2007.

- Barnett et al. [30] describe a hospital evacuation in Southern California to avoid damage from wildfires in 2009.

In the following sections, we summarize the lessons learned and needs for improvement as listed in these papers. They are categorized as considerations for predisaster planning, decision making, patient care and transportation, staffing, recordkeeping, and communication.

\subsection{Pre-disaster Planning for Complete Evacuations}

Some of the lessons learned pertain to architectural or design concerns. For example, services that are critical to patient care - pharmacy, nursing units, etc. - should not be placed in areas that may be affected by flooding [20,24]. When essential services are unnecessarily damaged, an evacuation that might otherwise be avoidable may be required. During Hurricane Katrina, generators were damaged and facilities were forced to evacuate. Gray and Hebert [24] suggest that had they been placed in areas that were not subject to flooding, some of the post-storm conditions may not have been as dangerous. Even when generators are used as a means of backup power, it is important for the staff to consider that power outages may not be temporary [20] and that generators are not likely to support requirements for a facility to operate [8, 24, 27], and evacuations may be necessary.

As mentioned before, every facility is required to have an evacuation plan in place. These should be reviewed and updated on a regular basis [22]. Most hospital evacuations are caused by internal emergencies such as fires and utility failures, but hospitals should plan for multiple hazard types based on their hazard vulnerability [11]. To be effective, multiple possible receiving facilities should be identified prior to an emergency event $[21,24,25]$. Planners must also consider that certain types of emergencies may affect multiple local hospitals [11, 22, 23]. Local facilities should be identified to receive patients from facilities that are affected by an internal emergency, 
and non-regional facilities should be identified for external emergencies that may affect an entire community. In these cases, patients may have to travel longer distances to be relocated to safety. These types of regional emergencies may also cause demands at a hospital to increase.

In addition, community-wide disasters will place increased demands on transportation resources [8, 12, 21, 28]. During external emergencies, other local facilities may have to shut down, so plans must include guidelines for how to handle new patients $[24,28]$. Since a hospital is considered a resource in an emergency, plans should also include how to handle the non-patient population that arrives seeking basic needs such as food, water, or shelter [23, 24]. Even nursing homes may become vital community resources [26]. Good relationships with local organizations such as churches, nursing homes, and school systems may provide additional opportunities for resources [22] whether it be supplies, water, or transportation.

Evacuation plans should include backup policies and devices to handle power loss $[20,23,27]$. This includes generators as discussed above as well as batteries for flashlights, methods for recording patient information, and alternates for equipment such as ventilators and medication storage systems. In addition, backup plans for communication $[12,20,23,26,29]$ and patient care $[11,20,24,30]$ are essential. In the more recent papers, the authors suggest that patients, staff, and equipment (medical equipment, supplies, etc.) may need protection during or after the evacuation [23, 24, 29].

Facilities that may be at a higher risk for evacuation may benefit from planning at a much lower level. Creating unit-specific "evacuation packs" that include patient worksheets, important contact information, and the supplies necessary to take care of patients will help save critical time when evacuation orders are given [22]. Whether this level of planning is appropriate for a facility depends on how the management views the risks and benefits which will be further discussed in the next section.

Finally, the majority of nursing homes surveyed after Hurricanes Katrina and Rita indicated that nursing home facilities need more considerations for preparations or response in public health emergencies planning $[8,12,21,25,26]$.

\subsection{Decision Making}

Whether planning for a potential disaster or facing an actual emergency, decisionmakers must balance the uncertainty, risks, costs, and the narrowing window for evacuations [24]. This includes deciding whether to evacuate in advance when an emergency is forecasted. If the risks of transporting patients are far greater than sheltering-in-place, it is likely that a facility will choose not to move the patients. If the nature of the emergency threatens to affect the facility's ability to provide care, the facility must decide if and when to evacuate. Obviously, the probability of predicting where a hurricane will make landfall increases as the time until landfall decreases. If patients are moved too soon, the forecasted event may not affect the facility at all. "Unnecessary" evacuations put patients at otherwise avoidable risks, and they are expensive for the facility. An advanced evacuation, however, may allow the facility access to resources that may decrease in availability as the time window decreases. Making the decision not to evacuate in advance may lead to some of the well-publicized 
complications that are reviewed in the papers that discuss the aftermath of Hurricane Katrina [23, 24], though advanced evacuation still puts the patients at a variety of risks. Dosa et al. [31] discuss the issues inherent in evacuating frail patients from nursing homes and how this may influence the decision to evacuate. As part of their call for additional research in this area, they pose a framework for assessing the risk based on three key elements - the individual patient, the facility, and the emergency event. Such an approach to quantifying risk could be used in deciding whether to evacuate or not, as well as in prioritizing patient transfers once a decision to evacuate has been made.

If a hospital or nursing home is going to evacuate patients, there are no established guidelines about how to prioritize patients for transfer. Typically, triage refers to allocating scarce medical resources to a surge of incoming patients. Patients are chosen for treatment by determining who will benefit the most. In the context of a healthcare facility evacuation, patients may be "triaged" to determine the best prioritization scheme. The Center for Bioterrorism Preparedness and Planning [32] suggests that patients that require the most assistance should be transferred away from the facility first. Gray and Hebert [24] agree with this strategy for advanced - or pre-disaster evacuations. The Association for periOperative Registered Nurses (AORN) [33] and the New York Centers for Terrorism Preparedness and Planning [34] suggest that patients should be prioritized from least to most critical. There are no models, case studies, etc., however, to support these prioritization strategies [24, 32 - 34]. Schultz [7] suggests that the effectiveness of triage decisions depends on the situation. Prioritizing patients will be further discussed in the final section of this paper as an example of engineering contributions for improving healthcare facility evacuations. Regardless of the strategy chosen to move patients, a staff member with knowledge of the current patient roster is critical to patient "triage." There should be multiple staff capable of filling this role so that there is someone on site at all times [20].

\subsection{Patient Care and Transportation}

Facilities operators need to consider that vehicles other than ambulances can be used to move patients. If the emergency affects the availability of transportation resources or routes, other forms of alternate transportation may be required [6, 12, 20, 21, 23-25]. Access to transportation resources has been identified as an issue during evacuations, particularly for nursing homes $[8,12,21]$. Since multiple facilities may have contracts with the same transportation service providers, demands may exceed availability during community-wide emergencies.

Even though some long-term care facilities had planned arrangements for patient transfers, so many other facilities were overwhelmed by Hurricanes Katrina and Rita. These facilities may have also been forced to evacuate or may have already reached capacity. Therefore, the intended receiving facilities were unavailable [12, 21]. In addition, hospitals may not be prepared or willing to accept critical patients [8]. One third of the nursing homes surveyed indicated that they were unable to find a place to transfer their special needs residents, and they were required to shelter in place [21]. Particularly for nursing home patients, transport may negatively impact health $[8,12]$.

Depending on the type of emergency and the conditions at the receiving facilities, it may be easier for a facility to choose to send all of its patients to a single facility. In the 
case of the bomb threat [22], the patient population was small enough - and the capacity at a receiving facility large enough - that all of the staff could move with the patients to continue care. This allowed for less planning and paperwork. When it is not possible to redistribute the staff for uninterrupted care, sending patients to multiple facilities helps to avoid overwhelming a single facility [20]. If a receiving facility cannot immediately accept patients, there must be a plan in place for continuing patient care outside of the facility [7, 30].

Patients' special requirements and limitations should be considered when preparing them for transport $[8,12,21,23-26,28]$, and coordinating patients in vehicles leads to better utilization of the resource [20]. Particularly for older patients, stretchers or other equipment for transporting patients may be difficult to use and time-consuming [21]. Charts [22, 24] and medications [22] should travel with the patient, and patients should have some sort of identification attached to them [21, 24]. For longer travel, supplies for heating and cooling the patients, as well as food and water, will need to be transported with patients $[12,26]$. Finally, family members and volunteers may either help [20,24] or hinder [24, 29] evacuation efforts. In some cases, family members can assist with patient transfers, but in other cases, they may add to the problem by disturbing the clinical staff or seizing scarce resources.

\subsection{Staff}

There are not many lessons learned that discuss staffing plans, roles, or requirements, though it seems intuitive that an evacuation is highly dependent on staff's participation and cooperation. Most of the papers stress the importance of having evacuation plans, and authors stress the importance of training the staff to understand the plan $[6,22,25]$. As mentioned above, certain patient types may be difficult to transport, and may require the coordination and use of many staff resources [21]. Most of the papers credit their staff for participation, teamwork, and response.

Whether patients are assigned to be transported to a single receiving facility or to multiple ones, some authors suggest that the staff should be reassigned to the new facilities to continue caring for patients $[6,20]$.

Though most nursing homes indicated that they had sufficient staff to evacuate patients during the 2004 hurricanes, maintaining adequate staffing levels throughout the 2005 evacuations was difficult $[8,12,21]$, and in some cases, the administration had to enforce staff participation [21]. Allowing the staff to travel with their families - or allowing families to come into the facility - may improve staffing levels [25].

\subsection{Record-keeping}

Once patient transfers are underway, there should be systems in place for tracking the patients $[24,27,29]$ as well as a system to monitor bed availability at area hospitals [27]. Because loss of electricity may be a result of the disaster, a hard copy list of patient transfers should be maintained [22] at both the transferring and receiving facilities [20]. In addition, equipment transfers should be monitored [20], and a system that tracks costs would be beneficial [22]. 


\subsection{Communication}

Clearly, reliable communication and coordination are essential to patient transfers [20, $22,23]$ and potentially the most important factors that contribute to a successful evacuation [23]. This includes having back-up plans in place as discussed in Section 2.1. Though communication channels are described as contributing to the success of the Southern California evacuation, communication was determined to be the area that needed the most improvement in the debriefing session [30]. The lessons learned from the nursing home evacuations during Hurricanes Katrina and Rita indicate that there should be improvements between the staff and physicians or medical directors before moving patients [25]. Communication needs to flow within the facility as well as to the receiving facilities $[20,23,24]$.

One less obvious communication-related consideration relates to the media's effect on the evacuation. Bowers et al. [6] suggest that communication with the media is important. Healthcare facilities can utilize the media to communicate where patients have been transferred or if there is any damage that would prevent providing care to incoming patients. However, the media may broadcast inaccurate information. This should certainly not be a primary concern, but the administrators should be aware that the media may be present and may have an effect on the public's perception of the event [23].

\section{CURRENT RESEARCH AND THE NEED FOR ENGINEERING CONTRI- BUTIONS}

In this section, we briefly reference the current engineering contributions related to healthcare facility evacuations. There are a number of papers that focus on each of the topics addressed in the following sections - healthcare facility design, evacuation plans, making the decision to evacuate, pre-evacuation times, and selection of evacuation routes and resources - but there are limited sources that address these with respect to evacuations. For example, there are a variety of modeling approaches for determining or examining traffic assignments during emergencies [e.g., 14 - 16]. The papers presented in this section focus specifically on research related to improving complete healthcare evacuations. As mentioned before, facilities would prefer not to shut down; perhaps this is why the stream of literature directly related to full facility evacuation is limited.

\subsection{Healthcare Facility Design}

Ünlü et al. [35] present a space syntax model to consider the navigation issues during a hospital evacuation. The authors cite the shape of the building and evacuation routes, ergonomics, and characteristics of the occupants as the main factors that influence circulation out of a hospital during an evacuation. The model can be used to test designs for new facilities and analyze weaknesses as related to patient evacuations.

Various risk assessment techniques can be used to identify potential hazards, but it is difficult to estimate how these risks may further complicate patient evacuations. For example, certain emergencies may affect exit routes, elevators, or equipment. Congestion in corridors or smoke in the air may slow evacuation times or alter routes. Instead of staging several drills to test the various combinations of complications 
scenarios, Johnson [17] created a simulation model of the evacuation of Glasgow Hospital and considered the various risks to estimate the average and worst-case evacuation times.

\subsection{Evaluating Evacuation Plans}

By examining more than 2,000 nursing home evacuation plans, Castle [36] determined the elements that were most often excluded: staffing procedures for the evacuation (44\%), plans for coordination with the community (42\%), reentry to the facility (40\%), consideration of residents' medical and personal needs (37\%), maintaining water supply $(36 \%)$, consideration of residents' personal belongings (35\%), and pre-identified evacuation routes and travel time estimates (31\%).

In her dissertation, McGlown [5] suggests that hospital evacuations plans are often only written to meet the standards set by accrediting agencies. Vogt [37] surveyed nursing home facilities and used Quarantelli's model to evaluate the threats, resources, social climate, and other extracommunity factors as they relate to the effectiveness of an evacuation. While many of the issues are common to general population evacuations, Vogt identifies the need for different evacuation strategies for dependent populations.

\subsection{Deciding to Evacuate and Pre-evacuation Times}

Various researchers have attempted to model the factors that influence how a person responds to a threat of an emergency including when to evacuate or whether to leave at all [e.g., 38 - 40]. This research, however, focuses on the general population. These factors are different for healthcare facilities where the occupants face greater risks during transport. In addition, most occupants of a healthcare facility are a dependent population, and they rely on direction and assistance from the staff as well as the availability of transportation and other resources. McGlown's [5] main research focus is to consider the variables that contribute to a healthcare facility's decision to evacuate, and they fall into five categories: infrastructure impediments, event monitoring, time and risk factors, the internal environment, and the external environment. She presents a conceptual model for making a decision to evacuate based on these factors.

Gwynne et al. [41] study pre-evacuation times - the difference between the time an occupant started to evacuate and the time the evacuation order was given - at a university residence hall and at a hospital. In the hospital case study, the authors point out that the behavior of the staff directly affects the patients' response to - and activities during - an emergency. They suggest that any hospital evacuation model should include some element to represent pre-evacuation time, but the factors that affect preevacuation time need further research.

\subsection{Selection of Evacuation Routes and Resources}

In the event of an external, regional disaster, other healthcare facilities - as well as the general population - may also be evacuating, and the patients may have to compete for transportation resources including vehicles and routes. If an internal emergency forces a facility to evacuate, the facility may have access to additional resources to help with an evacuation.

The Agency for Healthcare Research and Quality (AHRQ) [42] provides a web- 
based evacuation planning tool for healthcare facilities. Based on the user's input assumptions, including the number and types of available transportation resources as well as the number and types of patients to be evacuated, the model provides estimates for the times to evacuate patients and utilization of the transportation resources. Patients are classified by their transportation requirements, and the assumption is that this reflects their acuity. Patients' relocation assignments are made such that the sickest patients are transferred to the closest facilities to reduce travel time.

Tayfur and Taaffe [43] use simulation to evaluate various scenarios for evacuation time requirements. In a second paper, Tayfur and Taaffe [44] present a model to determine the allocation of staffing and transportation resources during a pre-specified evacuation window that minimizes cost. Though the authors do not incorporate traffic simulation, they instead include a traffic congestion factor to include additional delays in travel times.

Duanmu et al. [45] study emergency and evacuation planning at healthcare facilities in combination with an external disaster that forces the general population and healthcare facilities to simultaneously evacuate. The authors create a traffic simulation model to analyze the interaction and the effects on evacuation time, delays, and routes. The model can be used to test various evacuation start times by estimating travel times between the evacuating and receiving facilities. A case study of the Charleston, South Carolina metropolitan area indicated that in order to evacuate all patients from a large hospital prior to a hurricane's landfall, a hospital evacuation should begin no less than 12 hours prior to the community's mandatory evacuation orders, or both can begin simultaneously if both the hospital and community evacuations begin 2 days prior to landfall.

\subsection{Opportunities for Research}

Based on the summary of lessons learned in Section 2 and the previous research summarized in Section 3, the following have been identified as potential areas of research for engineering improvements. This list represents the opportunities for engineers to make contributions to improving evacuations.

- How can a facility improve their evacuation planning even before it is built? How can the locations and shapes of stairwells, hallways, and ambulance pick-up bays affect patient movement?

- Under what risks should a healthcare facility evacuate given advanced notice of a potential threat?

- How much time is required to complete an evacuation, and when should a facility make the decision to evacuate? How do pre-evacuation and transport times vary by the type of emergency? By patient type?

- How can the various risks and rewards be quantified, measured, and modeled?

- How do staffing patterns change when patients need to be evacuated? Qureshi et al. [46] examine the staff's "ability and willingness to report to duty during catastrophic disasters," and Chaffee [47] discusses the impact of disasters on nurses and the ethical dilemmas associated with reporting to work. However, the authors are not aware of any research that discusses staffing requirements or behaviors during an emergency evacuation from a healthcare facility. 
- How should receiving facilities be chosen, and how should patients be assigned to receiving facilities?

- How should transportation resources be allocated? How are allocation decisions affected when only a single facility is evacuating or when an entire community is evacuating? Or when multiple healthcare facilities have to evacuate?

- Transportation includes more than just the vehicles; what methods can be used to improve patient movements throughout the evacuation - from their beds to their final destination?

- What is the best way to track patient transfers?

- How can costs be quantified and tracked?

- "The impact of transfer, the breakup of potential social networks, and the disruption of worker-residents relationships on residents' psychological wellbeing...should be explored" [21].

- What are the objectives of healthcare facility evacuation, and what are the appropriate prioritization strategies (discussed in Section 4).

- How can facilities work together during community-wide disasters?

- How should re-entry into the facility be managed?

\section{EXAMPLE: PRIORITIZING PATIENTS FOR EVACUATION}

In this section, we shift from the broad overview of issues in healthcare facility evacuation to focus on a discussion of a specific component. The authors' particular research focus has been on developing models to determine patient prioritization strategies for healthcare facility evacuations [48]. A typical planning assumption of a full facility evacuation is that all patients will be evacuated. In some cases, however, the limited availability of resources may reduce the number of patients that can be transported away from the facility.

Triage methodologies are based on the utilitarian concept, and the goals of conventional triage are more obvious. To contribute to the overall good, scarce resources should be allocated to those that will benefit the most from medical treatment. However, triage methodologies are intended to determine priorities for patient care during or after a trauma event $[33,49]$ - not when the resources are also victims of the emergency. Therefore, traditional algorithms do not necessarily apply to the evacuation of medical patients [50].

In most evacuation plans, there is no documentation for which patients should be transported first, or if transporting a patient actually adds more risk. As mentioned in Section 2.2, there are differing opinions about how patients should be prioritized for transport. It is agreed that the objective of triaging patients is to do the most good for the most amount $[49,50]$. This follows the utilitarian perspective of ethical reasoning, but what is "good" in an evacuation? Is the goal to get the most number of patients out of the building, decrease costs of the evacuation, save the most lives, or increase the quality of life for patients after the evacuation - or some combination of these? How does the nature of the emergency affect the objectives of patient transfer? Kraus et al. [49] support the idea that the objective of triage may vary depending on the emergency.

When there is limited time or resources to evacuate, the plan should include a patient classification scheme that provides operators guidance in making decisions concerning 
the order in which patients should be transported. The authors have proposed a twophased modeling approach including dynamic programming and discrete-event simulation [48]. First, the authors model a healthcare facility evacuation as a Markov decision process. Depending on the scenario, patients can be classified by acuity, relative location to the emergency, etc., such that patients groups have the same rate of evacuation, rate of natural deaths, and probability of a successful evacuation. For now, patient classification groups are limited to two. This decreases computing time but would also be more realistic for actual implementation.

To give an example, the authors include simplifying assumptions in hopes of identifying policy structures and guidelines. Consider a system where there are $N$ patients to be evacuated, and these patients fall into one of two categories: critical care patients and non-critical care patients. The state of the system can be represented as the number of each patient type remaining, i.e. $\left(X_{1}, X_{2}\right)$.

The output of the dynamic program returns a number to represent from which patient group the next evacuee should be chosen for every combination of patients remaining in the system (e.g., Figures 1 and 2). The authors are currently testing multiple objectives and scenarios by including or excluding rewards for evacuees, penalties for deaths, and holding costs for the patients in the system. For example, assume that critical care patients are Type 1 patients and non-critical care patients are Type 2 patients. Based on acuity, it is fair to assume that non-critical care patients would be quicker to transport, would have a slower death rate, and would have a higher probability of a successful evacuation. If the objective is to get the most patients out of the system, then the policy should be to evacuate all of the non-critical care patients first before beginning to evacuate the critical care patients (Figure 1). Now consider that holding costs are included. It is fair to assume that it costs more to hold a critical care patient in the system. Depending on the values chosen for rewards, penalties, and holding costs, the policy may be a switching policy (Figure 2) rather than a "greedy" policy. In these cases, patient evacuations would begin by evacuating the non-critical care patients but switch to critical care patients at some point. After evacuating all critical care patients, all remaining non-critical care patients would be evacuated.

To test the policies determined with the dynamic program, the authors have created a simulation to estimate the number of evacuees and deaths as well as the average and maximum times needed to complete a full evacuation.

In a complex healthcare environment, decisions will be made according to some type of strategic plan and incident command system. The conclusions for patient priorities depending on the objective - are presented as high-level guidelines, but they are based on a variety of detailed, data-driven research. These detailed decisions are being modeled not to be written directly into plans, but to be used to educate staff on the impact of a variety of evacuation objectives and scenarios.

The authors continue to test various objectives and evaluate the policies for "ethical fitness" [50]. By summarizing prioritization schemes for various scenarios, this research can be used to develop generalized guidelines to be included in evacuation planning such that some of the decision responsibility can be transferred from the clinical staff and incident command. This will allow them to focus on their primary objective - to safely evacuate patients. 


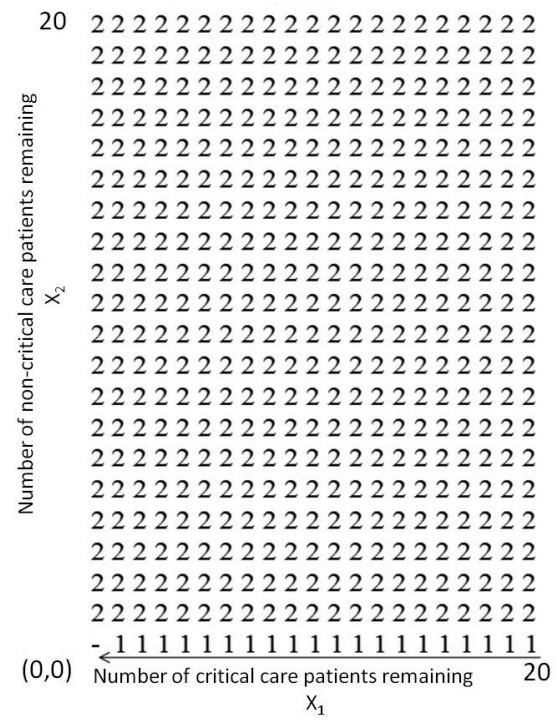

Figure 1. Greedy Policy Structure ${ }^{1}$

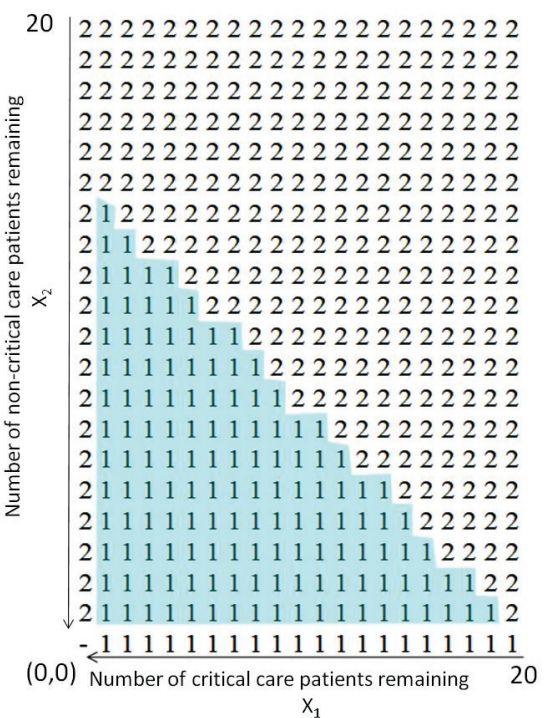

Figure 2. Switching Policy ${ }^{2}$

\footnotetext{
1,2Figures 1 and 2 represent which patient type should be evacuated at any combination of Type 1 (critical care patients) or Type 2 (non-critical care) patients remaining in the system for a facility that starts with 20 patients of each type to be evacuated.
} 


\section{CONCLUSIONS}

Whether or not an emergency allows for some sort of decision window, the success of an evacuation is largely dependent on the real-time decision making at all levels of the organization. In order for an evacuation plan to be implemented effectively, it must be laid out in great detail. However, it is difficult to create a complete and comprehensive plan. As shown in the previous section, some of the strategies that are essential to the evacuation have not been researched, and there are differing opinions on how evacuations should be carried out.

Engineers have the opportunity to research strategies to improve healthcare facility evacuation planning by combining the lessons learned from previous evacuations with a number of technical concepts. By modeling decisions mathematically, researchers can improve strategies and take some of the responsibility away from the clinical staff which will allow them to deliver the highest quality of care to their patients.

\section{REFERENCES}

1. Schultz, C. and Stratton, S. Improving Hospital Surge Capacity: A New Concept for Emergency Credentialing of Volunteers, Annals of Emergency Medicine, 2007, 49(5), 602-609.

2. Hick, J., Barbera, J. and Kelen, G., Refining Surge Capacity: Conventional, Contingency, and Crisis Capacity, Disaster Medicine and Public Health Preparedness, 2009, 3(1), S59-S67.

3. Peleg, K. and Kellermann, A., Enhancing Hospital Surge Capacity for Mass Casualty Events, Journal of the American Medical Association, 2009, 302(5), 565-567.

4. Argon, N., Ziya, S. and Righter, R., Scheduling Impatient Jobs in a Clearing System with Insights on Patient Triage in Mass Casualty Incidents, Probability in the Engineering and Informational Sciences, 2008, 22(3), $301-332$.

5. McGlown, K., Determinants of the Evacuation of Health Care Facilities, PhD Dissertation, University of Alabama at Birmingham, 1999.

6. Bowers, P., Maguire, M., Silva, P. and Kitchen, R., Everybody Out!, Nursing Management, 2004, 35(4), 50-54.

7. Schultz, C., Koerig, K. and Lewis, R., Implications of Hospital Evacuation after the Northridge, California, Earthquake, The New England Journal of Medicine, 2003, 348(14), 1349-1355.

8. Dosa, D., Grossman, N., Wetle, T., and Mor, V. To Evacuate or Not to Evacuate: Lessons Learned From Louisiana Nursing Home Administrators Following Hurricanes Katrina and Rita, Journal of the American Medical Directors Association, 2007, 8(3), 142-149.

9. Taaffe, K., Kohl, R. and Kimbler, D., Hospital Evacuation: Issues and Complexities, in: Kuhl, M., Steiger, N., Armstrong, F. and Joines, J., eds., Proceedings of the 2005 Winter Simulation Conference, Orlando, 2005, 943-950

10. Schultz, C., Koenig, K., Auf der Heide, E. and Olson, R., Benchmarking for Hospital Evacuation: A Critical Data Collection Tool, Prehospital and Disaster Medicine, 2005, 20(5), 331-342.

11. Sternberg, E., Lee, G. and Huard, D., Counting Crises: US Hospital Evacuations, 1971 - 1999, Prehospital and Disaster Medicine, 2004, 9(2), 150-157.

12. Nursing Home Emergency Preparedness and Response during Recent Hurricanes, 2006, United States Department of Health and Human Service, Office of Inspector General, OEI-06-06-00020.

13. Quarantelli, E., Evacuation Behavior and Problems: Findings and Implications from the Research Literature, 1980, Disaster Research Center, Ohio State University, Columbus, Ohio. 
14. Pidd, M., de Silva, F. and Eglese, R., A Simulation Model for Emergency Evacuation, European Journal of Operational Research, 1996, 90(3), 413-419.

15. Hobeika, A. and Kim, C., Comparison of Traffic Assignments in Evacuation Modeling, IEEE Transactions of Engineering Management, 1998, 45(2), 192-198.

16. Cova T. and Johnson, J., A Network Flow Model for Lane-based Evacuation Routing. Transportation Research Part A, 2003, 37(7), 579-604.

17. Johnson C., Using Computer Simulations to Support a Risk-based Approach for Hospital Evacuation, 2006, Technical Report, Glasgow Accident Analysis Group, University of Glasgow.

18. NIMS Resource Center, Federal Emergency Management Agency, U.S. Department of Homeland Security, Web. 18 Nov. 2009. <http://www.fema.gov/emergency/nims>.

19. Center for HICS Education \& Training, Hospital Incident Command System, Washington Hospital Center and Kasier Permanente, Web. 18 Nov. 2009. <http://www.hicscenter.org/>

20. Cocanour, C., Allen, S., Mazabob, J., Sparks, J., Fischer, C., Romas, J. and Lally, K., Lessons Learned From the Evacuation of an Urban Teaching Hospital, Archives of Surgery, 2002, 137(2), 1141-1145.

21. Hyer, K., Brown, L., Berman, A. and Polivka-West, L., Establishing and Refining Hurricane Response Systems for Long-term Care Facilities, Health Affairs, 2006, 25(5), 407-411.

22. Augustine, J and Schoettmer, J., Evacuation of a Rural Community Hospital: Lessons Learned From an Unplanned Event, Disaster Management \& Response, 2005, 3(3), 68-72.

23. Bovender Jr., J. and Carey, B., A Week We Don't Want to Forget: Lessons Learned from Tulane, Frontiers of Health Services Management, 2006, 23(1), 3-12.

24. Gray, B. and Hebert, K., Hospitals in Hurricane Katrina: Challenges Facing Custodial Institutions in a Disaster, Journal of Healthcare for the Poor and Underserved, 2007, 18(2), 283-298.

25. Castro, C., Persson, D., Bergstrom, N., and Cron, S. Surviving the Storms: Emergency Preparednes in Texas Nurisng Facilities and Assisted Living Facilities, Journal of Gerontological Nursing, 2008, 34(8), 9-16.

26. Laditka, S., Laditka, J., Xirasagar, S., Cornman, C., Davis, C., and Richter, J. Providing Shelter to Nursing Home Evacuees in Disasters: Lessons From Hurricane Katrina, American Journal of Public Health, 2008, 98(7), 1288-1293.

27. Hyer, K., Brown, L., Christensen, J., and Thomas, K. Weathering the Storm: Challenges to Nurses Providing Care to Nursing Home Residents during Hurricanes, Applied Nursing Research, 2009, 22, e9-e14.

28. Disaster Preparedness: Limitations in Federal Evacuation Assistance for Health Facilities Should be Addressed, 2006, United States Government Accountability Office, Report to Congressional Committees, GAO-06-826.

29. Lewis, S. Georgia Hospital Hit by F3 Tornado - All Patients Evacuated Through the ED, ED Management Tornado, 2007, 19(4), 37-39.

30. Barnett, J., Dennis-Rouse, M. and Martinez, V., Wildfire Disaster Leads to Facilities Evacuation, Orthopaedic Nursing, 2009, 28(1), 17-20.

31. Dosa, D., Hyer, K., Brown, L., Artenstein, A., Polivka-West, L., and Mor, V., The Controversy Inherent in Managing Frail Nursing Home Residents During Complex Hurricane Emergencies, Journal of the American Medical Directors Association, 2008, 9(10), 599-604.

32. Center for Bioterrorism Preparedness and Planning. Evacuation Planning for Hospitals Draft Document, 2006.

33. AORN Guidance Statement: Mass Casualty, Triage, and Evacuation, AORN Journal, 2007, 85(4), 297-304. 
34. New York Centers for Terrorism Preparedness and Planning, Hospital Evacuation Protocol, 2006.

35. Ünlü, A, Ülken, G. and Edgü, E., A Space Syntax Based Model in Evacuation of Hospitals, in: van

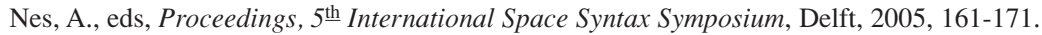

36. Castle, N. Nursing Home Evacuation Plans, The American Journal of Public Health, 2008, 98(7), $1235-1240$.

37. Vogt, B., Issues in Nursing Home Evacuations, International Journal of Mass Emergencies and Disasters, 1991, 9(2), 247-265.

38. Sorensen, J., When Shall We Leave? Factors Affecting the Timing of Evacuation Departures, International Journal of Mass Emergencies and Disasters, 1991, 9(2), 153-165.

39. Perry, R. and Lindell, M., The Effects of Ethnicity on Evacuation Decision-Making, International Journal of Mass Emergencies and Disasters, 1991, 9(1), 47-68.

40. Fischer, J., Stine, G., Stoker, B., Trowbridge, M. and Drain, E., Evacuation Behaviour: Why Do Some Evacuate, While Others Do Not? A Case Study of the Ephrata, Pennsylvania (USA) Evacuation, Disaster Prevention and Management, 1995, 4(4), 30-36.

41. Gwynne, S., Galea, E., Parke, J. and Hickson, J., The Collection and Analysis of Pre-evacuation Times Derived from Evacuation Trials and Their Application to Evacuation Modeling, Fire Technology, 2003, 39(2), 179-195.

42. Mass Evacuation Transportation Planning Model, Agency for Healthcare Research and Quality, US Department of Health and Human Services, Web. 22 Sept. 2009. $<$ http://massevacmodel.ahrq.gov/(X(1)S(2rp4lf55pbtftr55zk0ktm21))/Home.aspx>.

43. Tayfur, E. and K. Taaffe, 2009. A Model for Allocating Resources during Hospital Evacuations, Computers and Industrial Engineering, in press.

44. Tayfur, E. and K. Taaffe, 2009. Simulating Hospital Evacuation - The Influence of Traffic and Evacuation Time Windows, Journal of Simulation, in press.

45. Duanmu, J., Taaffe, K. and Chowdhury, M. Minimizing Patient Transport Times During Mass Population Evacuations. Research Report, 2009, Department of Industrial Engineering, Clemson University.

46. Qureshi, K., Gershon, R., Sherman, M., Straub, T., Gebbie, E., McCollum, M., Ewrin, M., and Morse, S. Health Care Workers' Ability and Willingness to Report to Duty during Catastrophic Disasters, Journal of Urban Health, 2005, 82(3), 378-388.

47. Chaffee, M.W. Making the Decision to Report to Work in a Disaster, American Journal of Nursing, 2006, 106(9), 54-57.

48. Childers, A.K., Visagamurthy, G. and Taaffe, K., Prioritizing Patients for Evacuation from a Healthcare Facility, Transportation Research Record: Journal of the Transportation Research Board, 2009 , in press.

49. Kraus, C., Levy, F. and Kelen, G. Lifeboat Ethics: Considerations in the Discharge of Inpatients for the Creating of Hospital Surge Capacity, Disaster Medicine and Public Health Preparedness, 2007, $1(1), 51-56$.

50. Klein, K. and Nagel, N., Mass Medical Evacuation: Hurricane Katrina and Nursing Experiences at the New Orleans Airport, Journal of Emergency Nursing, 2007, 5(2), 56-61. 


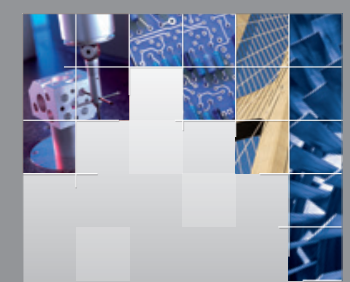

\section{Enfincering}
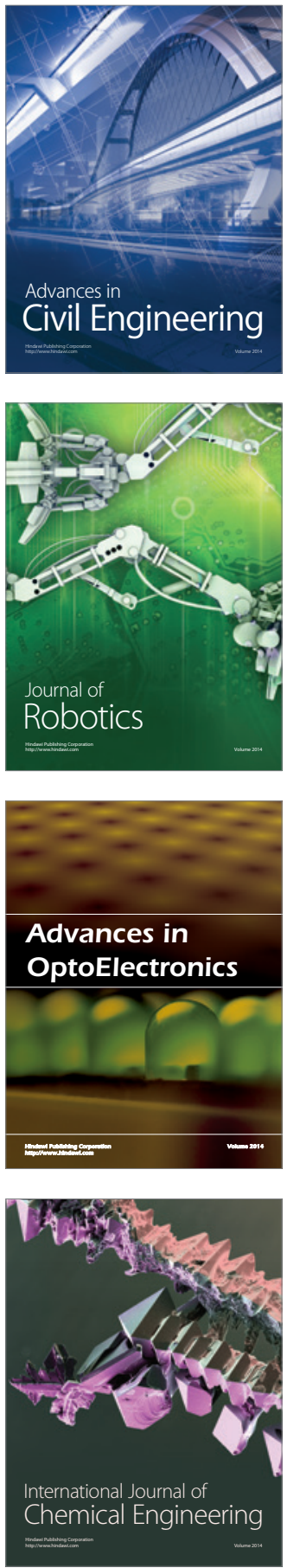

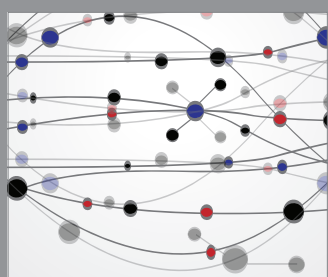

The Scientific World Journal

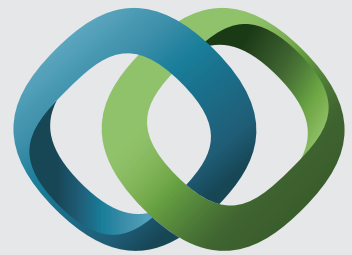

\section{Hindawi}

Submit your manuscripts at

http://www.hindawi.com
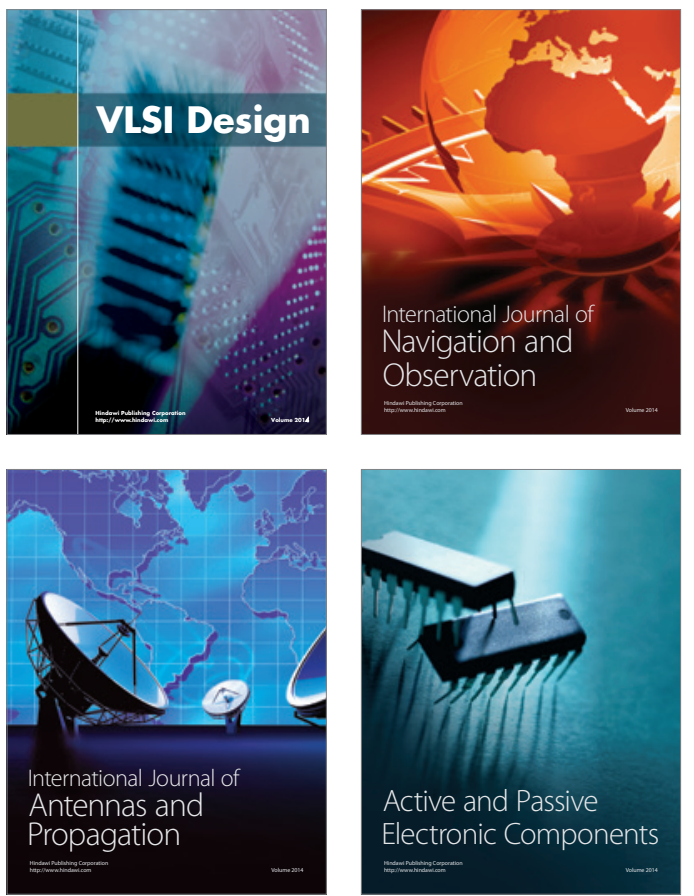
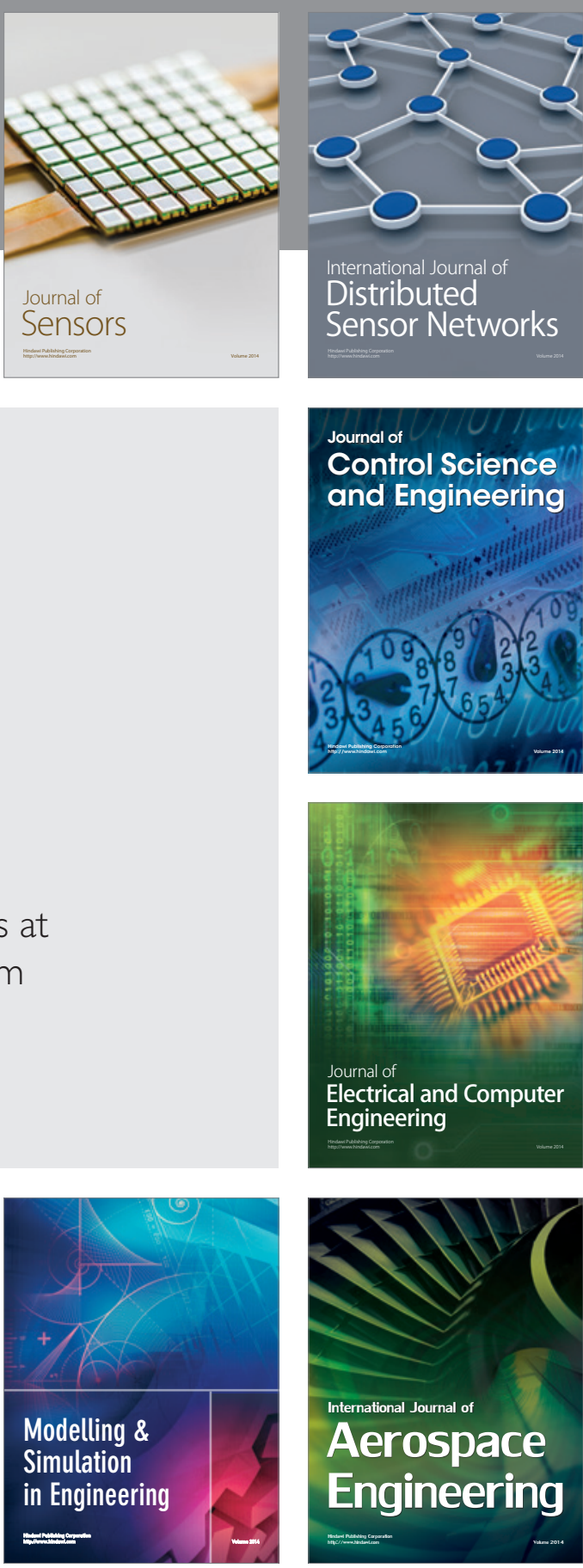

International Journal of

Distributed

Sensor Networks

Journal of

Control Science

and Engineering
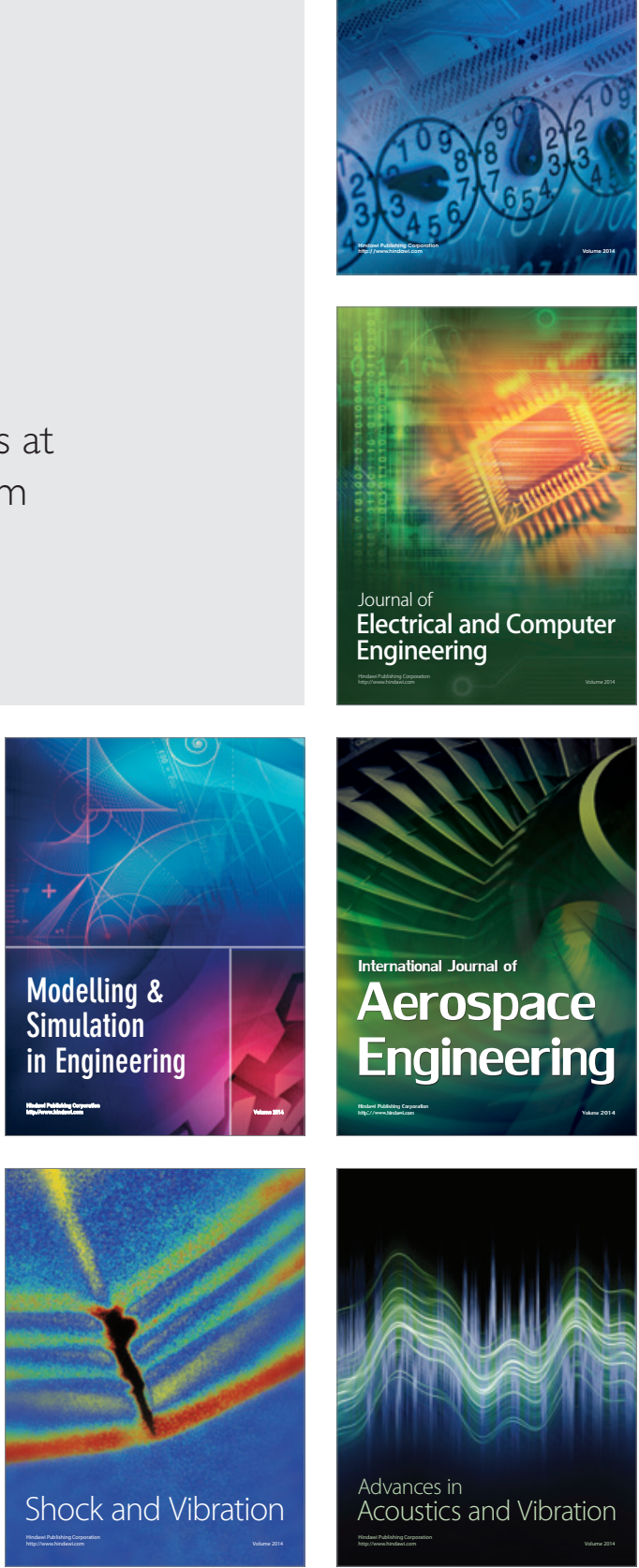